\title{
Kristeva e Butler: significância, performatividade e produção como parâmetros para uma semiótica crítica
}

\author{
Cássio de Borba Lucas' \\ https://orcid.org/0000-0003-1642-8274 \\ Alexandre Rocha da Silva' \\ https://orcid.org/0000-0003-2366-5163 \\ I - UFRGS \\ Porto Alegre (RS), Brasil
}

Resumo: O artigo propõe um diálogo entre as teorias de Julia Kristeva e Judith Butler com o objetivo de retomar suas contribuições para uma semiótica crítica da comunicação. Indica, para tanto, uma série de ressonâncias que parecem conectar os distintos projetos das autoras em um similar viés pós-estruturalista. Na primeira seção, são exploradas estas ressonâncias por meio das noções de "experiência discursivamente condicionada", de "práticas significantes" e da possibilidade de "intervenção crítica" na comunicação com viés desconstrucionista. Na segunda seção, trata-se de indicar a centralidade, no pensamento das duas pensadoras, do conceito de produção, que parece fundamentar as perspectivas da significância e da performatividade de que cada uma lança mão para evidenciar os desafios micropolíticos da comunicação.

Palavras-chave: significância; performatividade; produtividade; semiótica.

Abstract: Kristeva and Butler: significance, performativity and production as parameters towards a critical semiotics - This article proposes a dialogue between Julia Kristeva and Judith Butler's theories, with the goal of exposing their contributions to a critical semiotics of communication. It indicates, therefore, a series of resonances that seem to connect the distinct projects of both authors in the same post-structuralist vein. In the first section, these resonances are explored through the notions of "discursively conditioned experience", "signifying practices" and the possibility of a "critical intervention" in communication based on deconstruction. In the second section, the effort is to indicate the centrality and productivity, in both the authors' thoughts, of the concept of production, which seems to fundament the theories of significance (Kristeva) and performativity (Butler) as critical perspectives towards a micropolitics of communication.

Keywords: significance; performativity; productivity; semiotics. 


\section{Introdução}

Tanto em Judith Butler quanto em Julia Kristeva, reconhecemos uma abordagem pós-estruturalista da semiótica. A primeira, de forma menos declarada, em seus trabalhos sobre gênero, sexualidade e feminismo com que podemos travar contato em seu livro mais conhecido, lançado em 1990 (BUTLER, 2016); a segunda, marcadamente, em um momento de ebulição da semiótica europeia. Podemos assinalar esta primeira fase de Kristeva entre os anos 60 e 1974. Neste período, em que produziu seus textos mais influentes para o pensamento semiótico, suas matrizes teóricas de interlocução eram, principalmente, a linguística estruturalista, o materialismo histórico, a fenomenologia e a psicanálise. Psicanálise esta que assume forte primazia no pensamento da autora franco-búlgara, marcando, de 1974 em diante, a quase totalidade de seus escritos teóricos.

A maior parte dos escritos de Kristeva sobre o feminismo aparece nesta segunda fase, e é a ela, principalmente, que Butler dedica sua atenção quando faz uma extensa crítica da perspectiva kristevana (BUTLER, 1990, pp. 141-164). Apesar desta crítica, e das diferenças que podemos flagrar entre as autoras, muitas delas assinaladas pela própria Butler, afirmamos que uma preocupação central com a perspectiva crítica de onde se parte é comum a ambas, embora tematizada diferentemente. Neste sentido, o diálogo de seus textos nos remete à ratificação de alguns princípios que fundamentam a própria pesquisa pós-estruturalista. Onde se reconhece este pós-estruturalismo de Butler e Kristeva? Procuramos, neste artigo, responder a esta questão tendo em vista a produtividade do debate que as autoras incitam para uma semiótica que se pretende crítica de seu próprio procedimento.

O objetivo deste estudo, neste sentido, está ligado à problemática de trabalho da pesquisa corrente do GPESC (Grupo de Pesquisa Semiótica e Culturas da Comunicação), intitulada Semiótica Crítica. O GPESC reconhece, na história da semiótica, três fases distintas. A primeira fase, de descoberta, rompe com o modelo tradicional de representação, pelo qual as linguagens eram consideradas o suporte representativo de um mundo pré-representacional (referente). Em contraposição, postula-se que o signo não se refere ao mundo, mas é uma associação de significado e significante (Saussure) ou uma ação de geração de signos em signos que traduzem mais completamente o objeto dinâmico (Peirce), o qual, contudo, sempre se apresenta mediadamente. É a significação que formaliza o referente.

Esta reviravolta na concepção da representação engendra uma segunda fase paradoxalmente a mais rica e a mais enclausurante - de produção de modelos. O sucesso da linguística estruturalista de Saussure e seguidores, que chegou às unidades mínimas de descrição da linguagem oral, por exemplo, incita, neste período, a tentativa de investigar os mais diversos sistemas de signos por uma abordagem similar. Na investigação de semióticas tão díspares como a gestualidade e o cinema, chegou-se a uma série de modelos altamente formais. Foi-se demonstrando, porém, "cada vez mais, que os modelos formulados pela linguística formal não são onivalentes, e que os diversos modos de significação devem 
ser estudados independentemente deste cume-limite [de formalização] a que chegou a linguística" (KRISTEVA, 1981, p. 326).

Estes modelos, longe de serem tomados como prescrições de possíveis a priori (o que acaba acontecendo em alguns casos), devem ser elaborados e revisados, a cada investigação, no rumo de um terceiro momento pós-estruturalista da semiótica - que Kristeva (2012, p. 24) já concebia, aliás, como uma tarefa de crítica da ciência e de seus próprios modelos. No escopo dessa terceira fase, os trabalhos do GPESC pretendem ampliar o debate semiótico à luz das teorias contemporâneas que problematizam a comunicação.

Em uma primeira etapa, investigou-se a perspectiva das materialidades da comunicação na medida em que revigoram a discussão de conceitos como a tradução, a noção de representamen, a noção de imanência, o próprio conceito de signo etc. Na segunda etapa (corrente), procura-se discutir as implicações que a semiótica, compreendida como epistemologia, retira da discussão queer, pós-humana e micropolítica. Daí a pertinência da produção pós-estruturalista das autoras aqui estudadas, produção que se conjuga no trabalho sobre alguns conceitos importantes para a reflexão micropolítica de uma semiótica crítica.

A questão micropolítica, cuja formulação podemos retomar de Guattari e Deleuze, situaria os problemas de comunicação em um espaço irredutível à linguística: a comunicação é antes questão de política (DELEUZE; GUATTARI, 2012, p. 102). Desta formulação, decorre uma investigação não das regras, já abstratas, a que o estruturalismo podia chegar na descrição da língua como tendo primazia à fala; mas sim dos processos de institucionalização destas regularidades e codificações, processos que instituem efeitos comunicacionais de sentido, mas que são indissociáveis das redes de corpos, instituições e tecnologias em que são produzidos micropoliticamente. A abstração, neste sentido, deve ir mais adiante, no rumo das condições que possibilitam a emergência das regras de significação.

Esta problemática micropolítica parece-nos mostrar seu aspecto linguageiro e literário em Kristeva, enquanto Butler investigará seu aspecto de gênero, sexualidade e identidade. Cada autora resolve sua questão por meio de conceitos diferentes; mas são estes conceitos que nos interessam na medida em que têm pertinência, conjuntamente ou não, para o pensamento contemporâneo de uma micropolítica da comunicação, que aponta para a formalização da expressão tanto linguística quanto sexual.

Assim, estruturamos este trabalho em duas partes: na primeira, apresentamos a obra das autoras de modo a retomar apontamentos de Kristeva e Butler como uma série de ressonâncias em que é perceptível o solo teórico pós-estruturalista comum à abordagem de ambas (ao menos nos textos em questão): as noções de experiência e de identidade discursivamente condicionadas, o ocultamento dos jogos de força que regulam a significação, o conceito de prática significante, a perspectiva desconstrucionista que conecta ambas a Derrida, e também a centralidade do conceito materialista de produção. Destas ressonâncias, a última, que investigamos na segunda parte do trabalho pelos conceitos de significância (Kristeva) e de performatividade (Butler), parece fundamental 
à teoria das duas autoras, bem como à problematização micropolítica da comunicação como um desafio contemporâneo.

\section{A abordagem pós-estruturalista de Butler e Kristeva}

Butler (2016, p. 10) situa sua obra em um momento de reconhecimento de que "não é mais certo que a teoria feminista deva tentar resolver as questões da identidade primária para dar continuidade à tarefa política". Ou, mais diretamente: "a identidade do sujeito feminista não deve ser o fundamento da política feminista" (BUTLER, 2016, p. 25). Isto, insistiremos, não quer dizer um abandono da política representativa ou de todo tipo de institucionalidade, pela proposição de um 'fora' apolitizado. Pelo contrário, significa reconhecer as limitações do modelo representativo (a criação de exclusão como consequência das lógicas identitárias), sua maleabilidade fundamental e a capacidade de interferir praticamente na produção dessa institucionalização de identidades.

Não se pretende pensar fora do "campo contemporâneo do poder" (BUTLER, 2016, p. 23). Com isso encontramos ecos estruturalistas na perspectiva de uma imanência e de uma intertextualidade radicais, em que antes do texto e ao redor dele há somente linguagem (BARTHES, 1974, p. 6), nunca um fora transcendental da estrutura. Da mesma forma, a identidade é sempre efeito de "práticas de legitimação" (BUTLER, 2016, p. 24), que merecem, justamente por isso, uma "genealogia crítica" (BUTLER, p. 23-24) de suas formas. Daí a tarefa não de situar 'o feminino' como uma dimensão prévia à cultura masculinista, uma dimensão que devamos resgatar, mas sim de investigar seus processos de criação no seio mesmo desta cultura.

Ressalte-se que, se o estruturalismo já se fundamentava em uma prática "imanente" que não abordava a linguagem de fora, mas de dentro (HJELMSLEV, 1991, p. 32), o pós-estruturalismo de um Derrida, por exemplo, veio a acusar o próprio Saussure, fundador do estruturalismo (embora não usasse o termo), de reintroduzir um "fora da estrutura" (DERRIDA, 1971, p. 230), um "significado transcendental" (DERRIDA, 1972, p. 30) no interior da sua concepção de signo, pela figura do significado enquanto conceito. Também Kristeva (2012, p. 64) vai criticar em Saussure a "anterioridade da consciência individual para a instituição social". Do estruturalismo ao pós-estruturalismo, em suma, ressoa, com cada vez mais radicalidade, a afirmação da imanência como fundamento necessário aos estudos de comunicação.

A crítica de Derrida ressalta a conexão de um fora transcendental com uma presença plena a si, com uma "auto-afecção" (DERRIDA, 2012, p. 497) que aparece como um centro ausente da estrutura (DERRIDA, 1971, p. 230). Este centro seria prévio à cultura e poderia instituí-la. Eis o que o autor acusa, em toda história do pensamento, de ser a "metafísica da substância" - expressão retomada por Butler (2016, p. 49) e reformulada em seu debate como "visão do gênero como substância" (BUTLER, 2016, p. 53). 
No mesmo sentido, Butler não admite um "sexo como pré-discursivo" ou como fora do campo do poder. Pelo contrário, "regimes muito diferentes de poder produzem os conceitos de identidade sexual" (BUTLER, 2016, p. 45), produzem o sexo como pré-discursivo (BUTLER, 2016, p. 28), como fora da estruturalidade que o produz.

Podemos situar esta questão como uma primeira ressonância entre Butler e Kristeva: o reconhecimento de uma "experiência discursivamente condicionada" (BUTLER, 2016, p. 30) do sujeito. Trata-se da absorção, por ambas, da tradição semiótica, linguística e estrutural a que viemos fazendo menção. Desta perspectiva, o sujeito não tem primazia sobre sua expressão: o falante é que é falado pela língua (língua que lhe permite se expressar ao mesmo tempo em que limita essa expressão por seu conjunto de regras). "O sujeito", afirma Kristeva (1981, p. 16) com Benveniste, "se forma e se transforma no discurso"; e é na linguagem que "se faz e se desfaz o sujeito falante" (KRISTEVA, 1981, p. 263). Já Butler exemplifica o modo como a "linguagem constitui o domínio imaginável do gênero" (BUTLER, 2016, p. 31) com o próprio fato de que "não é possível significar as pessoas na linguagem sem a marca do gênero" (BUTLER, 2016, p. 50), tanto no caso da língua francesa quanto no da inglesa.

A significação, assim, apresenta regras que passam, por exemplo, por uma "função de remate" (KRISTEVA, 2012, p. 74). A comunicação, assim, "organiza" "escolhas" (estes termos, em Kristeva, são pungentes, retirados de sua neutralidade aparente): o sujeito é homem ou mulher? Butler criticará com ênfase esses procedimentos de regulação, muitas vezes por binarização. A "linguagem [...] estrutura o mundo pela supressão dos múltiplos significados [...] e pela instauração de significados unívocos e discriminados em seu lugar" (BUTLER, 2016, p. 141-2). A categoria do sexo, por exemplo, "é inevitavelmente reguladora" (BUTLER, 2016, p. 169), unificando "funções e significados corporais que não têm correlação necessária uns com os outros" (BUTLER, 2016, p. 169). O mesmo vale para a categoria dos sujeitos, que "são invariavelmente produzidos por via de práticas de exclusão que não 'aparecem'” (BUTLER, 2016, p. 19). Com o que chegamos a uma segunda ressonância: a experiência discursivamente condicionada é fruto de uma regulação que oculta seus próprios mecanismos.

Em Saussure, o sentido não pode ser um conhecimento imediato, tampouco uma simples representação em que o signo remete ao 'mundo'. O sentido é efeito de um fenômeno de significação, esta entendida como a associação entre "imagem auditiva e conceito" (SAUSSURE, 1995, p. 31), entre significante e significado. É com isto em mente que podemos dizer que a significação, neste modelo, esconde seu funcionamento, que decorre de uma "cristalização social" (SAUSSURE, 1995, p. 29) dada. Uma posição pós-estruturalista vai propor a investigação da própria produção desta associação, desta cristalização que automatiza a função sígnica, que coloca conceitos (supostamente préexistentes, pré-discursivos) por detrás de palavras, por assim dizer, em um "psiquismo que tem sua sede no cérebro" (KRISTEVA, 2012, p. 64). 
Tanto Kristeva quanto Butler vão criticar as posições que concebem a comunicação como transmissão de significados (estando estes já estabelecidos como os significados possíveis, passíveis de manifestação), acenando sempre para a exploração das regularidades hegemônicas que se invisibilizam no próprio aprendizado da linguagem. É necessário esquecer as regras de expressão para bem se expressar (e a significação, neste sentido, no melhor dos casos se oculta). Mas as regras não são só de expressão: como lembra a semiótica hjelmsleviana de Deleuze e Guattari (2012, p. 102), o agenciamento por que passa a significação "só formaliza a expressão em uma de suas faces; em sua outra face inseparável, ele formaliza os conteúdos". Assim, a linguagem não só oferece (e regula) um meio para expressar o gênero, para voltarmos à discussão de Butler. Ela enforma os próprios gêneros que vêm a ser expressos. Por isso "a noção de gênero [deve] ser reformulada, para abranger as relações de poder que produzem o efeito de um sexo pré-discursivo e ocultam, desse modo, a própria operação da produção discursiva" (BUTLER, 2016, p. 28).

A questão da regulação e de seu ocultamento remete, em outra ressonância de Butler e Kristeva, ao conceito de "prática significante" (BUTLER, 2016, p.225; KRISTEVA, 1975). Na segunda, este conceito recebe tratamento preciso: "chamaremos de prática significante a constituição e a travessia de um sistema de signos" (KRISTEVA, 1975, p. 11). Note-se de saída que constituição e travessia são somente aspectos de um mesmo movimento.

Por seu primeiro aspecto, uma prática significante estrutura as codificações por meio das quais se estabelece a significação. Retoma-se a noção de experiência discursivamente condicionada: é a "constituição do sistema de signos" que "exige a identidade de um sujeito falante em uma instituição social". O "modo de produção de signos", apesar do léxico marxista, não responde a uma lógica de superestrutura relativamente ao "modo de produção do conjunto socioeconômico". Eles mantêm uma relação de "pertencimento intrínseco", e o locus desse pertencimento é o sujeito falante (KRISTEVA, 1975, p. 11).

Este mesmo sujeito, identificado e regulado na significação, porém, é também atravessado pelo segundo aspecto da prática significante. Nele "se instaura", assim, uma relação entre "a unidade (fundamento do todo significante e social) e o processo que a precede e excede" (KRISTEVA, 1975, p. 11). A "instância unificante" está ligada à coerência do signo, do sistema e da socialidade, em "detrimento do processo", da travessia e do atravessamento das instituições sociais nas quais o sujeito se reconhecia previamente, o que nos leva, conforme a autora, a "momentos de ruptura, de renovação, de revolução da sociedade" (KRISTEVA, 1975, p. 12) que diríamos micropolíticos por sua operação imanente à prática significante e suas institucionalidades. Este processo, como veremos adiante, que instaura a significação, foi chamado de significância.

Com o conceito de prática significante e sua análise kristevana no caso da literatura, portanto, reconhecemos que não é o sujeito que se expressa na comunicação como prática social; ele é o depositário desta prática. Voltada para outra prática significante, Butler parece afirmar, semelhantemente, que não é o gênero que está em nós, mas nós que estamos no gênero. 
As operações de regulação da prática significante, contudo, não estão sempre já dadas - pelo contrário, a "significação censura a problemática do trabalho" (KRISTEVA, 2012, p. 386) de sua produção. Em grande parte é esta a advertência que Butler nos oferece acerca das discussões de identidade de gênero. O gênero, bem como o sexo e o corpo, "oculta sua genealogia e se apresenta sob a categoria de 'fato natural'” (BUTLER, 2016, p. 127). Hjelmslev (2013, p. 3) já alertava que "o perigo reside no fato de que a linguagem quer ser ignorada". É justamente esta cumplicidade entre regulação da significação e ocultamento de seus procedimentos que Kristeva procura abordar com o conceito de prática significante e sua distinção em significação (a comunicação como superfície estruturada e cristalina que se oculta) e significância (a comunicação como intervenção nestas estruturalidades). Como contestar a significação sem se situar em um terreno mítico, supostamente fora da prática significante, mas na verdade produzido por ela?

Questão que ressoa nas duas autoras aqui estudadas: a experiência discursivamente condicionada e ocultada é pensada por ambas pela conexão com Derrida, autor fundamental na bibliografia de Butler e interlocutor direto de Kristeva - que o ateste a poderosa entrevista que ele concede em 1968 (DERRIDA; KRISTEVA, 1972). Com o pensamento desconstrucionista, as autoras vão enfrentar o desafio de escapar à metafísica substancialista por meio, porém, de um discurso historicamente marcado por categorias ligadas a esta própria tradição. Butler dirá que "o substantivo 'eu' só aparece como tal por meio de uma prática significante que busca ocultar seu próprio funcionamento e naturalizar seus efeitos" (BUTLER, 2016, p. 249). É tarefa micropolítica derridiana criticar a linguagem por dentro de si própria: não há fora da língua que utilizaremos, mas esta língua nunca é "inocente ou neutra. Ela é a língua da metafísica ocidental" (DERRIDA; KRISTEVA, 1972, p. 29).

Para Butler (2016, p. 68), não havendo recurso a uma identidade "que escape à matriz de poder e às regulações discursivas que efetivamente produzem e regulam a inteligibilidade desses conceitos", torna-se necessário encontrar possibilidades de "inversão, subversão ou deslocamento efetivos" das "práticas reguladoras que produzem a categoria do sexo" como extra-linguístico. Esta questão, mais especificamente voltada à temática do gênero e da ação micropolítica feminista, parece repercutir o que Kristeva (1981, p. 12) já afirmava acerca da semiótica nos anos 60: "parece impossível, hoje, sem escapar ao terreno do materialismo, afirmar a existência de um pensamento extra-linguístico", tornando-se necessário vislumbrar nesse sistema de linguagem "não somente um sistema de comunicação, mas também a produção deste sistema" (KRISTEVA, 1981, p. 303).

Do reconhecimento dos limites da experiência discursivamente condicionada, somos conduzidos, por um mesmo gesto pós-estruturalista das duas autoras, à ideia de uma intervenção crítica na produção deste condicionamento discursivo em práticas significantes concretas. Argumentaremos, no restante deste artigo, que é esta questão da produção (muito distinta, como vimos, das lógicas de representação) que fundamenta os conceitos de significância e de performatividade de que cada autora lança mão para evidenciar os desafios micropolíticos da comunicação. 


\section{Notas para uma semiótica da produção: significância e performatividade}

Como vimos, uma prática significante apresenta, para Kristeva, dois aspectos. A significação - "linguagem que serve para comunicar" (KRISTEVA, 1984, p. 87) - funciona por uma estruturação de regras (gramaticais, por exemplo) codificadas, pressupondo, para sua compreensão, um sujeito de enunciação e um destinatário. Daí o adjetivo "superficial" (KRISTEVA, 2012, p. 7) para designar o espaço da significação como uma transmissão de sentido, uma superfície que, em sendo bem sucedida sua decodificação, como que desaparece para dar lugar ao "conteúdo informacional" (KRISTEVA, 2012, p. 279) transmitido. Contudo, a significação, abordada por sua transmissividade, oculta o trabalho de sua produção que a significância opera. Trata-se de passar de um estudo do sentido para um estudo da "produtividade pré-sentido" (KRISTEVA, 2012, p. 386).

A significância está ligada ao trabalho de "remanejamento" (KRISTEVA, 2012, p. 9) das próprias estruturas e códigos da significação. Ora, embora tenhamos falado primeiro em significação, o ponto fundamental é o reconhecimento de que esta significação é que constitui uma "recaída defasada" (KRISTEVA, 1972, p. 241) da significância. Momento em que ocorre a "cristalização social" (para retomarmos o termo de Saussure); momento em que se estabelece um "freio identitário" (como dirá Barthes) imposto à significância, a qual permanece, contudo, fundamentalmente móvel e produtiva. A significação é somente um rastro atualizado do movimento de significância.

Em que sentido a significância é uma produtividade? A investigação da significância deve colocar o "princípio de estruturação" de um texto "na própria matéria do estruturado" (KRISTEVA, 2012, p. 284). Ou seja, um texto pode ser analisado não por sua capacidade de comunicar, ligada às regras codificadas da significação, mas por sua capacidade de redistribuir as categorias gramaticais e remanejar suas leis semânticas: nesse ponto, aparece uma significância crítica, e não em termos representativos, como um comentário social, mas como exploração e intervenção nas possibilidades estruturais da comunicação: neste sentido é que "o trabalho da significância [...] atravessa a estrutura" (KRISTEVA, 1972b, p. 243).

É útil - para compreender a significância como dimensão da comunicação voltada para um trabalho processual que precede o signo e para uma produtividade que "ultrapassa e precede" o sentido (KRISTEVA, 2012, pp. 240-241) - recuperar a analogia formal que Kristeva estabelece entre as relações de trabalho-valor advindas da teorização de Marx. O autor distinguia entre a dimensão do produto, caracterizado por sua circulação e valor de troca, e a da produção, em que "o trabalho poderia ser apreendido fora do valor, isto é, aquém da mercadoria produzida e posta em circulação na cadeia comunicativa" (KRISTEVA, 2012, p. 30). O espaço da produção admite um trabalho antes do valor, uma produtividade antes do sentido.

A possibilidade que o pensamento marxista apenas vislumbrou de considerar este trabalho (que só se expressa enquanto valor de troca, mas que o fundamenta) equivaleria, 
em termos de comunicação, à consideração da significância como produtividade e do sentido como aparição e efeito desta significância, que é superficializada enquanto valor de troca estruturalmente determinado. Assim como o produto aparece por seu valor de troca, ligado à circulação, o signo aparece por sua significação, ligada às estruturalidades da língua, uma vez que esta é tomada como "regra de leitura eterna" (BARTHES, 1974, p. 2). O desafio da comunicação é investigar e interferir no movimento produtivo desta significação, que se oculta na representação sígnica, tomando "o caminho dinâmico da produção antes do próprio produto" (KRISTEVA, 2012, p. 33). Verificar, portanto, "a possibilidade de outros tipos de práticas significantes, estruturalmente diferentes da do 'sujeito' e do 'sentido' da comunicação discursiva" (KRISTEVA, 1972b, p. 242).

Embora estejamos tentando chegar ao cerne abstrato da teoria de Kristeva - ao discutir esta "semiótica da produção" em que a primazia é da significância, que só se dá a ver por seus efeitos de sentido, mas é irredutível a eles -, é necessário discriminar o domínio específico a que se conectava este pensamento investigativo que a autora chamava de semanálise. Seu objeto era a literatura, e mais especialmente a literatura e a poesia modernas (KRISTEVA, 1975, p. 13), ambas integradas a práticas significantes da linguagem verbal. A preocupação micropolítica de Kristeva, neste ponto, estava na 'processualização' que a significância impunha, no caso de certos textos específicos, às codificações hegemônicas da significação verbal. A autora substituía o estudo por literatura como representação, pois, por uma exploração das virtualidades comunicacionais da materialidade textual, no rumo de uma "semiótica da produção" (KRISTEVA, 2012, p. 33):

Estamos falando da prática literária [...] de Mallarmé, a de Lautréamont, a de Artaud... Esta prática, que já não é literatura, nem representação - simulacro de um exterior, [...] se apresenta conscientemente como uma exploração do mecanismo do funcionamento da língua/da significação (KRISTEVA, 1972, p. 243).

Muito embora as práticas significantes trabalhadas por Butler sejam outras, parecenos que a centralidade do conceito de produção a conduz para uma lógica similar à da significância como movimento do sentido, assinalando, porém, o dever crítico ligado a esta lógica nas questões de gênero. O gênero é somente uma recaída defasada, como dizia Kristeva, uma identificação que não precede a performatividade que a instaura.

O conceito de performatividade parece a contribuição fundamental de Butler às questões micropolíticas da comunicação. Retoma-se, com ele, a crítica à metafísica substancialista: se "a aparência de uma substância permanente ou de um eu com traços de gênero [...] é produzida pela regulação dos atributos segundo linhas de coerência culturalmente estabelecidas" (BUTLER, 2016, p. 55), reconhecemos, com isso, que uma "produção de natureza" (termo que convenientemente critica toda distinção naturezacultura) se impõe também na questão de identidade de gênero. Não há identidade de gênero que não tenha sido trabalhada e regulada socialmente, e nenhuma identidade 
de gênero que 'se expresse' em nossos gestos, atos, performances. Ao contrário, "essa identidade é performativamente construída pelas próprias 'expressões' tidas como seus resultados" (BUTLER, 2016, p. 5).

Em oposição à perspectiva "que fixa identidades a priori, podemos reconsiderar a história das identificações constitutivas sem a pressuposição de uma lei fixa e fundadora" (BUTLER, 2016, p. 121), mas sim ligada a determinadas práticas significantes concretas que Butler vai compreender, com Foucault, como espécies de epistemes. Daí decorre a proposta de passagem dos estudos do sexo para os estudos do movimento produtivo da sexualidade em diferentes epistemes ou mecanismos de construção de gênero (BUTLER, 2016, p. 28).

Ora, reconhecer as estruturalidades hegemônicas da significação de gênero não significa resignar-se diante delas, mas opor-lhes: a) uma "genealogia da ontologia do gênero e b) "uma sexualidade subversiva, que floresce antes da imposição da lei, após sua derrubada ou durante sua vigência, como desafio constante à sua autoridade" (BUTLER, 2016, p. 63). Parece ressoar, aqui, a tese de Marx (1987, p. 161) conforme a qual a "coincidência da alteração das contingências com a atividade humana e a mudança de si próprio só pode ser captada e entendida racionalmente como praxis revolucionária". A revolução cabível, aqui, porém, não é representacional ou estatal, mas micropolítica ou molecular, como queria Guattari (1981).

É interessante acrescentar que os trabalhos mais recentes de Judith Butler, expandindo sua visada temática ao abordar questões contemporâneas por sua "performatividade política" (BUTLER, 2018, p. 20), não se afastam, porém, de uma análise centrada na produtividade semiótica em um "campo de poder que age sobre e por meio dos corpos" (BUTLER, 2018, p. 125). Assim é abordada, por exemplo, a produção da vulnerabilidade e da precariedade, que "não são características essenciais", mas "processos de formação de gênero, os efeitos de modelos de poder que têm como um de seus objetivos a produção das diferenças de gênero que caminhem lado a lado com a desigualdade" (BUTLER, 2018, p. 125). A questão micropolítica parece também retomada na exigência de colocação da "vida possível de ser vivida no primeiro plano da política" (BUTLER, 2018, p. 20) - exigência que se coloca também, na dimensão comunicacional, pelo foco na "ação política expressiva" e na "possibilidade de expressão" como dimensão da performatividade (BUTLER, 2018, p. 20).

Este artigo procurou, para além do afastamento proposto pela própria Butler, mas relativo principalmente às obras de Kristeva a partir de 1974, apontar para uma série de ressonâncias no pensamento das duas autoras, principalmente ligadas às questões semióticas desenvolvidas pela 'primeira' Kristeva, em que a matriz psicanalítica ainda dialogava frontalmente com as perspectivas materialista, linguística e semiológica. Estas ressonâncias parecem-nos reiterar a importância de conceitos cruciais para uma semiótica crítica. A performance butleriana tem primazia sobre o gênero assim como a significância de Kristeva sobre a significação, ambas acarretando uma micropolítica da produção. 
Esta preocupação micropolítica com a produção repercute no próprio título do livro de Butler: não se trata de elucidar Problemas de gênero, mas de criá-los (BUTLER, 2016, p. 70). "Subversão de gênero" (BUTLER, 2016, p. 70), subversão da literatura, subversão micropolítica da comunicação.

Alexandre Rocha da Silva é professor do Programa de PósGraduação em Comunicação e Informação da UFRGS. É doutor em Ciências da Comunicação pela Unisinos e pós-doutor na Université de Paris III.

arsrocha@gmail.com

Cássio de Borba Lucas é doutorando em Comunicação e Informação pelo PPGCOM-UFRGS.

cassioborba@gmail.com

\section{Referências}

BARTHES, R. Théorie du texte. In: Encyclopedia Universalis. Paris,1974.

1989.

From work to text. In: The rustle of language. Berkeley, EUA: University of California Press,

BUTLER, J. Problemas de gênero. Rio de Janeiro, RJ: Civilização Brasileira, 2016.

Corpos em aliança e a política das ruas: notas para uma teoria performativa de assembleia. Rio de Janeiro, RJ: Civilização Brasileira, 2018.

DELEUZE, G.; GUATTARI, F. Mil Platôs - Vol. 2. São Paulo, SP: Editora 34, 2012.

DERRIDA, J. A estrutura, o signo e o jogo no discurso das ciências humanas. In: DERRIDA, J. A escritura e a Diferença. São Paulo: Perspectiva, 1971, pp. 229-249.

. The voice that keeps silence. In: STERNE, J. The sound studies reader. Nova lorque, EUA: Routledge, 2012, pp. 495-503. Seuil, 1972.

KRISTEVA, J. Sémiologie et grammatologie. In: DERRIDA, J. Positions. Paris, França: Ed. du

GUATTARI, F. Revolução molecular. São Paulo, SP: Brasiliense, 1981.

HJELMSLEV, L. Ensaios linguísticos. São Paulo, SP: Perspectiva, 1991.

. Prolegômenos a uma teoria da linguagem. São Paulo, SP: Perspectiva, 2013.

KRISTEVA, J. Semanálise e produção de sentido. In: GREIMAS, A. J. Ensaios de semiótica poética. São Paulo, SP: Cultrix, 1972, pp. 238-273.

La révolution du langage poétique. Paris, França: Éditions du Seuil, 1974. 
Mode de production et pratique signifiante. In: KRISTEVA, J. La traversée des signes. Paris, França: Ed. du Seuil, 1975.

Revolution in poetic language. Nova lorque, EUA: Columbia University Press, 1984.

Introdução à semanálise. São Paulo, SP: Perspectiva, 2012.

SAUSSURE, F. Cours de linguistique générale. Paris, França: Payot \& Rivages, 1995.

Artigo recebido em 16/07/2018

e aprovado em 04/10/2018. 